\title{
How do we identify acute medical admissions that are suitable for same day emergency care?
}

\author{
Authors: Catherine Atkin, ${ }^{\mathrm{A}}$ Bridget Riley ${ }^{\mathrm{B}}$ and Elizabeth Sapey ${ }^{\mathrm{C}}$
}

Medical emergencies causing unplanned hospital admission place considerable demands on acute healthcare services. Some patients can be assessed and treated through ambulatory pathways without inpatient admission, via same day emergency care (SDEC), potentially benefiting patients and reducing demands on inpatient services. There is currently considerable variation within acute medicine in aspects of SDEC delivery ranging from overall service design to patient selection methods. Scoring systems identifying patients likely to be successfully managed through SDEC services have been suggested, but evidence of utility in diverse populations is lacking. Specific scoring systems exist for some common medical problems, including cardiac chest pain and pulmonary embolism, but further research is needed to demonstrate how these are most effectively incorporated into SDEC services. This review defines SDEC and describes the variation in services nationally. It reviews the evidence for their clinical impact, tools to screen patients for SDEC and current gaps in our knowledge regarding service deployment.

KEYWORDS: acute medicine, same day emergency care, risk scoring, service design, admission pathways

DOI: $10.7861 /$ clinmed.2021-0614

\section{Introduction}

With over 500,000 unplanned admissions monthly in the UK, emergency hospital admissions place significant demands on healthcare services. ${ }^{1}$ Medical emergencies are the most frequent cause, requiring assessment through acute medicine services, ${ }^{2}$ predominantly through referral from emergency medicine (EM) departments, with a proportion referred directly by community

Authors: ${ }^{A}$ NIHR academic clinical lecturer in acute medicine, University of Birmingham, Birmingham, UK; ${ }^{B}$ specialty trainee in acute medicine, South Warwickshire NHS Foundation Trust, Warwick, UK; ' director of PIONEER Hub, Institute of Inflammation and Ageing, University of Birmingham, Birmingham, UK, and professor of acute and respiratory medicine and honorary consultant, University Hospitals Birmingham NHS Foundation Trust, Birmingham, UK primary care services. ${ }^{3}$ Despite an increase in overall case-mix complexity and acuity, the proportion of patients admitted to NHS hospitals following presentation at an emergency department has remained stable, ${ }^{4}$ although this leads to an overall increase in the number of admissions.

Up to $80 \%$ of hospital beds contain unplanned admissions; during times of increased pressure, such as winter or waves of the recent COVID-19 pandemic, increased unplanned admissions directly impact the delivery of elective services. ${ }^{5}$ Although many patients in acute medical services require further investigation and treatment, acuity varies and up to $30 \%$ of admissions are discharged within 24 hours of arrival to hospital. $3,6,7$ The fact that a proportion can be discharged home within hours of arrival ${ }^{8}$ suggests alternative treatment pathways could potentially avoid admission for a subset of these patients, while still providing necessary reassurance, investigation or treatment.

\section{Same day emergency care: definition and national variation}

Same day emergency care (SDEC) is the delivery of urgent care in a hospital setting without overnight inpatient admission. ${ }^{9}$ SDEC aims to benefit both patients and healthcare service providers, reducing demand on inpatient services and avoiding the risks associated with inpatient admission. ${ }^{8}$

Acute and general medicine teams deliver SDEC in ambulatory emergency care (AEC) units, ${ }^{10}$ usually identifying suitable patients based on an expectation of discharge, with mapped assessment and treatment pathways that do not include an overnight stay. Patients should receive assessment to ensure they are suitable for discharge before leaving hospital, and should be given appropriate safety-netting advice. ${ }^{11}$ Not all SDEC assessments and treatments need to be delivered within the same day, and patients can return on subsequent days, including for specialist outpatient services. Pathways to assess and exclude diagnoses in new admissions may be delivered alongside services providing specific procedures or treatment for selected conditions, ${ }^{12,13}$ for example ambulatory management of cellulitis requiring intravenous antibiotics. ${ }^{10}$ Within these general parameters, there is considerable variation in pathway design and delivery (Fig 1). ${ }^{14,15}$

In a recent survey of UK acute hospitals, $99 \%$ of responders reported that they deliver ambulatory emergency care. ${ }^{3}$ On average, 


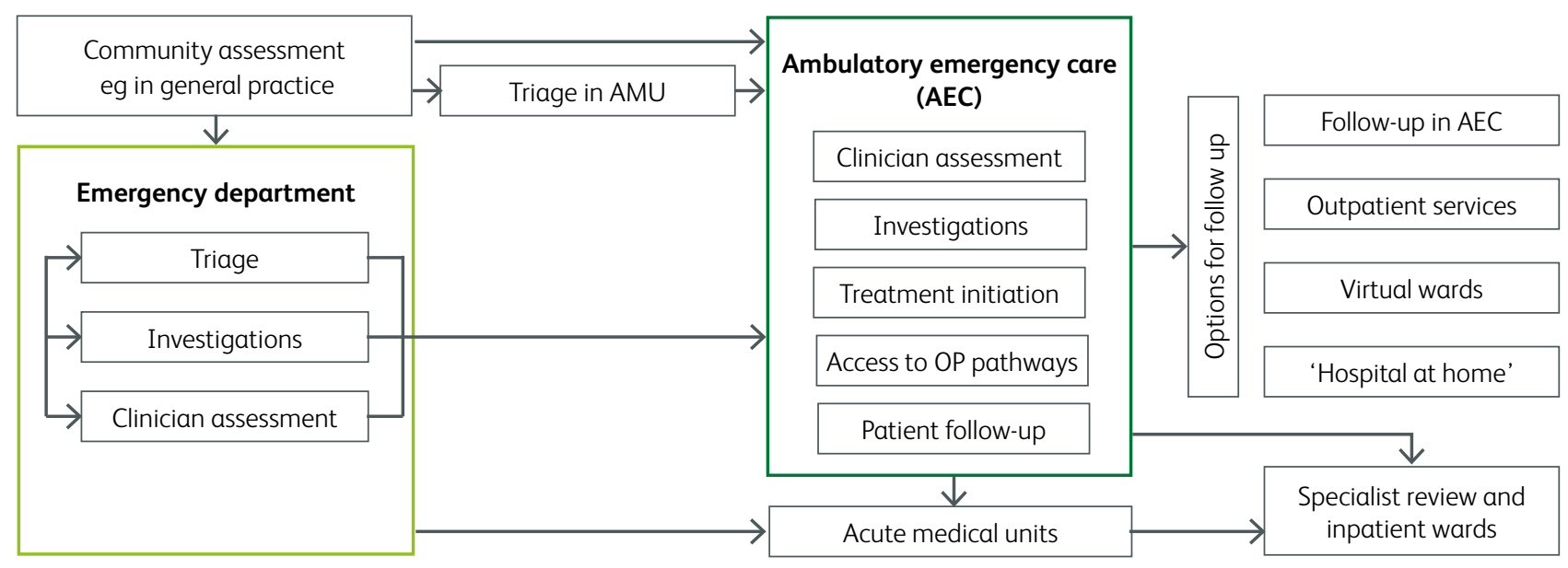

Fig 1. Ambulatory emergency care (AEC) pathways. Possible routes in the acute care admission pathway where patients can access AEC services, and the potential services delivered through AEC. OP = outpatient.

Table 1. Medical conditions suggested as suitable for same day emergency care

\begin{tabular}{|c|c|c|c|}
\hline Condition & Considerations & Condition & Considerations \\
\hline $\begin{array}{l}\text { Abnormal liver function } \\
\text { tests }^{a}\end{array}$ & $\begin{array}{l}\text { Requires access to appropriate } \\
\text { imaging modalities }\end{array}$ & \multirow{2}{*}{$\begin{array}{l}\text { Hypoglycaemia } \\
\text { in patients on } \\
\text { hypoglycaemic agents }^{a}\end{array}$} & $\begin{array}{l}\text { Requires full recovery from } \\
\text { hypoglycaemic episode }\end{array}$ \\
\hline \multirow[t]{2}{*}{ Anaemia $^{a}$} & \multirow{2}{*}{$\begin{array}{l}\text { Requires access to appropriate } \\
\text { pathways for investigation of } \\
\text { underlying cause }\end{array}$} & & \\
\hline & & $\begin{array}{l}\text { Inflammatory bowel } \\
\text { disease }^{a}\end{array}$ & $\begin{array}{l}\text { Symptoms and severity may } \\
\text { necessitate inpatient care }\end{array}$ \\
\hline \multirow[t]{2}{*}{ Ascites $^{a}$} & \multirow{2}{*}{$\begin{array}{l}\text { Requires access to appropriate imaging } \\
\text { modalities for assessment, and } \\
\text { procedural skills for management }\end{array}$} & $\begin{array}{l}\text { Known oesophageal } \\
\text { stenosis }^{a}\end{array}$ & $\begin{array}{l}\text { Requires appropriate pathways for } \\
\text { management }\end{array}$ \\
\hline & & $\begin{array}{l}\text { Lower respiratory tract } \\
\text { infection }^{a}\end{array}$ & $\begin{array}{l}\text { Requires identification of patients with } \\
\text { higher mortality risk }\end{array}$ \\
\hline Cellulitis (limb) ${ }^{a}$ & $\begin{array}{l}\text { May require pathways for outpatient } \\
\text { intravenous antibiotic therapy } \\
\text { Severe cases may require admission }\end{array}$ & $\begin{array}{l}\text { Non-specific abdominal } \\
\text { pain }^{\mathrm{b}}\end{array}$ & $\begin{array}{l}\text { Requires appropriate local pathways, } \\
\text { including involvement of surgical }\end{array}$ \\
\hline \multirow[t]{2}{*}{ Diabetes $^{a}$} & \multirow{2}{*}{$\begin{array}{l}\text { Requires exclusion of diabetic } \\
\text { ketoacidosis / hyperosmolar } \\
\text { hyperglycaemic state }\end{array}$} & & $\begin{array}{l}\text { specialties and access to appropriate } \\
\text { imaging }\end{array}$ \\
\hline & & Non-specific chest pain ${ }^{\mathrm{b}}$ & Requires identification of high-risk \\
\hline \multirow[t]{3}{*}{ End-of-life care ${ }^{a}$} & \multirow{3}{*}{$\begin{array}{l}\text { Requires access to specialist } \\
\text { multidisciplinary care } \\
\text { Requires appropriate facilities for } \\
\text { patient comfort and privacy } \\
\text { Requires consideration of patient } \\
\text { wishes }\end{array}$} & & patients with chest pain \\
\hline & & $\begin{array}{l}\text { PEG-related } \\
\text { complications }^{a}\end{array}$ & $\begin{array}{l}\text { Requires appropriately trained staff } \\
\text { Dependent on local PEG reinsertion } \\
\text { policy }\end{array}$ \\
\hline & & Pleural effusion ${ }^{a}$ & $\begin{array}{l}\text { Requires access to appropriate imaging } \\
\text { modalities for assessment, and }\end{array}$ \\
\hline \multirow{4}{*}{$\begin{array}{l}\text { Falls including syncope } \\
\text { or collapse }^{a}\end{array}$} & \multirow{4}{*}{$\begin{array}{l}\text { Requires exclusion of significant } \\
\text { underlying cardiovascular cause of } \\
\text { fall or collapse } \\
\text { Requires through assessment to } \\
\text { exclude acute illness precipitating } \\
\text { fall (that may necessitate hospital } \\
\text { admission) } \\
\text { Requires access to falls assessment } \\
\text { and therapy services, and return to } \\
\text { adequate mobility for discharge }\end{array}$} & & procedural skills for management \\
\hline & & $\begin{array}{l}\text { Transient ischaemic } \\
\text { attack (TIA) }{ }^{a}\end{array}$ & $\begin{array}{l}\text { May be appropriately managed } \\
\text { through outpatient pathways, eg } \\
\text { dedicated TIA clinic }\end{array}$ \\
\hline & & $\begin{array}{l}\text { Venous } \\
\text { thromboembolism }\end{array}$ & $\begin{array}{l}\text { Requires identification of instability and } \\
\text { raised mortality risk in suspected PE }\end{array}$ \\
\hline & & $\begin{array}{l}\text { including deep vein } \\
\text { thrombosis and } \\
\text { pulmonary embolism }\end{array}$ & $\begin{array}{l}\text { Access to appropriate imagining } \\
\text { pathways }\end{array}$ \\
\hline \multirow{2}{*}{$\begin{array}{l}\text { First seizure/seizure in } \\
\text { known epileptic }\end{array}$} & \multirow[t]{2}{*}{ Requires full recovery from seizure } & $(\mathrm{PE})^{a}$ & \\
\hline & & \multirow{2}{*}{\multicolumn{2}{|c|}{$\begin{array}{l}\text { 'Denotes conditions where NHS Ambulatory Emergency Care } \\
\text { Network estimates } \geq 60 \% \text { patients likely to be suitable for SDEC; } 12 \\
\text { bdenotes 'urgent care sensitive' conditions. }{ }^{46} \text { Surgical, obstetricl } \\
\text { gynaecological, or mental health related conditions have not } \\
\text { been included here. }\end{array}$}} \\
\hline Gastroenteritis $^{a}$ & $\begin{array}{l}\text { May require period of intravenous } \\
\text { treatment } \\
\text { Requires appropriate infection control } \\
\text { measures }\end{array}$ & & \\
\hline
\end{tabular}


$20 \%$ of patients admitted to acute medicine are seen through AEC; however, the proportion varies, with some centres seeing up to $75 \%$ of admissions through this route. ${ }^{14}$ This variation likely has multiple underlying causes. The local patient population may affect the number deemed suitable for SDEC, with some patient cohorts, such as the very elderly or pregnant patients, automatically excluded in some centres. ${ }^{16}$ Not all centres have additional services that facilitate AEC, such as outpatient parenteral antibiotic therapy (OPAT) or rapid access to specialist clinics. ${ }^{17}$

Despite variation in the provision and model of SDEC services, there are agreed performance indicators for comparison of services. These include measurement of a National Early Warning Score (NEWS) within 30 minutes of arrival, clinician assessment within 1 hour and use of validated condition-specific risk stratification tools. ${ }^{11}$ While it is recommended to monitor the proportion of admissions treated within SDEC, ${ }^{11}$ further evidence is needed regarding how many patients are likely to be suitable for, or benefit from, SDEC.

\section{Evidence for SDEC-driven improvements in care}

Delivering SDEC is a priority within the NHS and the current NHS Long Term Plan recommends that $30 \%$ of patients attending acute services should be treated via SDEC ${ }^{18}$ However, despite this policy drive, evidence of positive impact on patient care is currently limited.

There is evidence of the safety of ambulatory pathways for certain, specific conditions, such as pulmonary embolism, when using appropriate, disease-specific scoring systems, ${ }^{19}$ but robust evidence of benefit is lacking for most conditions seen through SDEC. For many medical conditions where it is suggested that a high proportion of patients may be suitable for SDEC (Table 1), ${ }^{12}$ evidence is limited on how to safely identify the patients that can be managed in this way, and how services could be most effectively structured to ensure benefit to patients and the wider healthcare system. Indeed, much of the evidence guiding SDEC relies on case studies of service development. ${ }^{20-22}$ No studies have compared different SDEC service models, or SDEC to usual care (hospital admission), the number of patients that may benefit from SDEC services remains unknown, and there are no health economics studies evaluating the cost effectiveness of SDEC. Despite this lack of evidence, SDEC pathway development for several conditions has been widely encouraged. ${ }^{12,20}$ For acute healthcare providers, there remains uncertainty as to which model to deploy, how to identify suitable patients, and what add-on services might be needed.

\section{Screening for SDEC suitability}

To effectively deliver SDEC, appropriate patients must be identified, with those likely requiring admission directed to acute medical units, and those most likely to be discharged home directed to SDEC. ${ }^{23}$ Two established scoring systems are available to identify SDEC patients from unselected medical admissions, ie medical admissions that have not been selected out as belonging to a specific medical specialty: ${ }^{20}$ the Ambulatory Care Score (Amb Score) and the Glasgow Admission Prediction Score (GAPS).

\section{The Ambulatory Care Score}

The Amb Score identifies patients likely to be discharged from hospital on the day of admission, and thus suitable for SDEC pathways. ${ }^{24}$ It can be used at multiple points in patient pathways, including primary care settings, is not disease-specific, and is recommended by the Royal College of Physicians. ${ }^{10}$

\begin{tabular}{|c|c|c|}
\hline Variable & & Points \\
\hline \multirow[t]{2}{*}{ Sex } & Female & 0 \\
\hline & Male & -0.5 \\
\hline \multirow[t]{2}{*}{ Age } & $<80$ & 0 \\
\hline & $\geq 80$ & -0.5 \\
\hline \multirow{2}{*}{$\begin{array}{l}\text { Access to personal transport/can take } \\
\text { public transport }\end{array}$} & Agree & +2 \\
\hline & Disagree & 0 \\
\hline \multirow[t]{2}{*}{ IV treatment not anticipated } & Agree & +2 \\
\hline & Disagree & 0 \\
\hline \multirow[t]{2}{*}{ Not acutely confused } & Agree & +2 \\
\hline & Disagree & 0 \\
\hline \multirow[t]{2}{*}{ MEWS $=0$} & Agree & +1 \\
\hline & Disagree & 0 \\
\hline \multirow{2}{*}{$\begin{array}{l}\text { Not discharged from hospital within } \\
\text { previous } 30 \text { days }\end{array}$} & Agree & +1 \\
\hline & Disagree & 0 \\
\hline
\end{tabular}

IV = intravenous, MEWS = Modified Early Warning Score..$^{82} \mathrm{An}$ Amb score $\geq 5$ aims to identify those likely to be discharged with 12 hours of assessment.

The Amb score was derived through a small single-centre cohort, with 282 primary care referrals for derivation, and 343 patients for validation. Outcomes were dichotomised as early discharge (within 12 hours) and admission ( $\geq 48$ hours); those admitted for $12-48$ hours were excluded. Factors influencing likelihood of early discharge were used to generate a score predicting early discharge (described in Table 2). An Amb score $\geq 5$ had $96 \%$ sensitivity (95\% CI 90 $98 \%$ ) and $62 \%$ specificity ( $95 \%$ CI 55-68\%) in identifying those likely to be discharged with 12 hours of assessment, and therefore suitable for SDEC.

A single-centre study of 200 acute medicine referrals in Taunton showed the Amb score had lower sensitivity in predicting early discharge than the original study, ${ }^{25}$ with a score $\geq 5$ having $88 \%$ sensitivity and $69 \%$ specificity. This may reflect local population differences, suggesting score performance varies with local demographics. Demographics or comorbidities of subjects were not reported, making it difficult to assess how these cohorts represent the population at large.

\section{Glasgow Admission Prediction Score (GAPS)}

The GAPS, derived from a multi-centre retrospective cross-sectional study of unscheduled EM attendances, estimates probability of inpatient admission at initial hospital triage. ${ }^{26}$ Variables were combined into a six-variable scoring system predicting admission 
Table 3. Glasgow Admission Prediction Score ${ }^{26}$

\begin{tabular}{|c|c|c|}
\hline \multicolumn{2}{|l|}{ Variable } & Points \\
\hline \multicolumn{2}{|l|}{ Age } & 1 point per decade \\
\hline \multicolumn{2}{|l|}{ NEWS } & $\begin{array}{l}1 \text { point per point on NEWS } \\
\text { score }\end{array}$ \\
\hline \multirow[t]{3}{*}{ Triage category } & 3 & 5 \\
\hline & 2 (or 3+) & 10 \\
\hline & 1 & 20 \\
\hline \multicolumn{2}{|l|}{ Referred by GP } & 10 \\
\hline \multicolumn{2}{|c|}{ Arrived in ambulance } & 5 \\
\hline \multicolumn{2}{|c|}{ Admitted $<1$ year ago } & 5 \\
\hline \multicolumn{3}{|c|}{$\begin{array}{l}\text { NEWS = National Early Warning Score. Specific cut-off scores to } \\
\text { predict admission have not been recommended for use in other } \\
\text { centres without local evaluation. }\end{array}$} \\
\hline
\end{tabular}

(Table 3). The GAPS also considers age and baseline physiology, as well as triage category at presentation, and, like the Amb score, is not disease-specific. The authors recognised the impact of local population demographics, and did not recommend specific cut-off scores for use in other hospitals, instead advising venues to conduct local validation to determine individualised thresholds. In North Glasgow, a GAPS > 15 to predict admission had $78.0 \%$ sensitivity (95\% CI $77.8-78.2 \%$ ), and $81.7 \%$ specificity (95\% CI $81.6-81.9 \%)$.

A single-centre study suggested EM triage nurses had higher accuracy in predicting admission when confident about the outcome (ie they estimated probability of admission to be $\geq 95 \%$ or $\leq 5 \%$ ) but the GAPS performed significantly better when the probability of admission was ranked between $6 \%-94 \%$ (the majority of cases in the clinical caseload studied). The best performance was obtained by overruling the GAPS in cases of high clinical certainty, suggesting clinicians consider factors when predicting admission that are not captured within the GAPS. ${ }^{27}$

Studies directly comparing the performance of the Amb and GAPS systems are limited. One comparison study suggests that the GAPS may predict inpatient admission for patients presenting to EM triage more accurately. This prospective cohort study of attendances at two large teaching hospitals in Glasgow and Sheffield found the GAPS to be a better predictor of discharge from hospital within both 12 and 48 hours, ${ }^{28}$ with cut-offs maximising sensitivity and specificity of GAPS $<18$ and Amb score $>5$. However, one of the centres was where the GAPS was originally derived, potentially impacting performance.

\section{Limitations of scoring systems}

There are a number of limitations to consider before embedding these systems within acute services.

Both systems were derived in single geographical areas and may be affected by local population demographics, impacting generalisability to the wider UK population. The Amb Score was derived and validated in rural Wales, ${ }^{24}$ while only $18.5 \%$ of the
UK population live in a rural setting. A higher proportion of the Welsh population identify as White British than most other UK regions. ${ }^{29}$ The GAPS was derived in Glasgow, ${ }^{26}$ which has poorer health outcomes and lower life expectancy than other major UK urban areas. ${ }^{30}$ While Glasgow's ethnic diversity has increased over recent years, non-White ethnic groups comprise less than $15 \%$ of the population, ${ }^{31}$ considerably lower than many other UK cities. ${ }^{32}$ Ethnicity is associated with the prevalence and age of onset of certain comorbidities, including cardiovascular disease, renal disease and diabetes, which may increase the need for inpatient admission. ${ }^{33}$

Using the Amb Score, women have an increased likelihood of discharge within 12 hours. This may be population-specific; the derived population is known for its historical coal mining industry, potentially increasing morbidity in men disproportionately. ${ }^{34}$ In the GAPS, ${ }^{26}$ women were significantly more likely to be admitted than men (not included in the final score due to small effect size (OR 1.2)). Using the Amb score, male patients over 80 years old, with no other negative features, would be deemed unsuitable for SDEC.

Implementation of the GAPS is further complicated by the need to validate binary cut-off levels within a specific population. ${ }^{26}$ This requires the skills and resource to undertake a robust analysis at each centre to determine appropriate cut-offs with acceptable sensitivity and specificity to predict admission.

There are also practical considerations when implementing the Amb score. Despite aiming to identify patients before full clinical assessment, a judgement predicting intravenous treatment is required, which may be difficult before reaching a diagnosis. Prediction without clinician involvement, for example incorporating machine learning, has not yet been investigated. Whether intravenous therapy does necessitate admission varies between services, and many hospitals have well-established OPAT services, with pilot studies suggesting other intravenous treatments, including diuretics, could be delivered effectively in alternative settings, reducing hospitalisation. . $^{35,36}$

Evaluation of score performance throughout the year is needed. The Amb Score was derived and validated from attendances in summer months. ${ }^{24}$ Acute services face additional pressures during winter, ${ }^{14}$ with seasonal variation in common presentations including respiratory diseases, ${ }^{37}$ and an increased average length of hospital admission, ${ }^{38}$ which likely impacts the need for admission for the unselected patient cohort overall.

Both the GAPS and Amb Score incorporate early warning scores (EWS). Previous research suggests a raised NEWS measured prehospital predicts inpatient admission and poor outcomes following admission. ${ }^{39,40}$ However, the single EWS measurement incorporated into the GAPS and Amb score may not fully reflect a patient's trajectory, with the change in EWS potentially more informative in directing clinical care, and a normal EWS does not equate to a low risk of morbidity or mortality in all patients. Since 2018, the more nuanced NEWS2 score, including new onset confusion and adjusted oxygen saturation ranges in patients with hypercapnic respiratory failure, has been mandated nationally in acute hospitals. ${ }^{41,42}$ The impact of incorporating the NEWS2 score in the GAPS and Amb score has not been evaluated.

\section{Stratification after initial diagnostic tests}

The GAPS and Amb scores are designed for unselected medical cohorts, early in patient pathways before a diagnosis is suspected. However, deploying scoring systems later in admission pathways 
may still prevent prolonged admission. Two clinical examples include patients requiring exclusion of acute coronary syndromes (ACS $)^{43}$ or pulmonary embolism (PE). These conditions often present with shortness of breath and chest pain, the most common presenting symptoms in acute medical services..$^{24}$ For these conditions, diagnosis-specific scoring systems are likely more appropriate in the first instance, alongside blood biomarkers.

\section{Suspected cardiac chest pain}

Chest pain accounts for 5-10\% of emergency hospital admissions, 44,45 with approximately 41 people per 1,000 population attending annually due to non-specific chest pain. ${ }^{46}$ Although some patients have serious underlying causes, half of those presenting to the emergency department have non-cardiac, non-specific or musculoskeletal pain. ${ }^{47}$ Many of these causes could be managed within SDEC where they require further assessment. Currently, evaluation with 12-lead electrocardiogram and high-sensitivity troponin I or T measurement on arrival, with further testing guided by a validated risk stratification tool, is recommended for suspected cardiac chest pain. ${ }^{48}$ Risk stratification tools assessing clinical features include the Emergency Department Assessment of Chest Pain Score (EDACS) ${ }^{49}$; History, Electrocardiogram, Age, Risk factors and Troponin (HEART) score ${ }^{50}$ and Thrombolysis in Myocardial Infarction (TIMI) score..$^{51}$ Comparison of these tools showed the EDACS could rule out acute MI in $48.3 \%$ of patients with suspected cardiac chest pain, with a sensitivity of $96.1 \%$, suggesting $3.9 \%$ of those with acute MI would be falsely reassured..$^{52}$

Some high-sensitivity troponin assays can rule out MI in chest pain starting $>1$ hour ago with a single measurement. ${ }^{47} \mathrm{~A}$ low (but possibly abnormal) level on first measurement requires repeat testing after one hour, with acute MI ruled out if there is no increase. ${ }^{47}$ Meta-analysis found this strategy had sensitivity $>98 \%$, a negative predictive value (NPV) of $>99 \%$, and specificity of $>90 \%$; however, the positive predictive value (PPV) varied between $50 \%-75 \%$, suggesting a high number had acute MI identified as a possible diagnosis, but later excluded on further investigation. ${ }^{53}$ This testing approach ruled out acute MI in $55 \%$ of patients with suspected cardiac chest pain and could be incorporated into SDEC pathways.

\section{Pulmonary embolism}

Investigation and management through ambulatory pathways is recommended for a subset of patients with diagnosed or suspected PE. Early discharge with follow-up through ambulatory or outpatient services is recommended for low-risk patients with confirmed PE, defined by risk stratification tools including the Pulmonary Embolism Severity Index (PESI) or simplified PESI (sPESI)..$^{54}$

These tools combine independent predictors of 30-day mortality in PE, incorporating age, gender, comorbidity and clinical features including tachycardia and hypotension, to identify patients at low risk of mortality. Using the PESI, 30-day mortality is $\leq 1.6 \%$ in 'very low risk' patients and $3.6 \%$ if 'low risk, ${ }^{55}$ with these two categories comprising approximately half of patients with PE. ${ }^{56}$ The sPESI dichotomises risk as low or high with approximately a third of cases classified as low risk, with $1 \% 30$-day mortality. ${ }^{57}$

This relies on prompt access to appropriate imaging to confirm the diagnosis within timescales allowing delivery of SDEC. ${ }^{58}$ However, these same tools can facilitate ambulatory investigation of suspected $\mathrm{PE}$, with patients identified as low risk receiving anti-coagulation treatment before discharge home, subsequently returning for confirmatory imaging through AEC services. ${ }^{54}$

Similar approaches may identify patients at low risk of adverse outcome for ambulatory investigation of specific symptoms, including jaundice ${ }^{59}$ or upper gastrointestinal bleeding (using the Glasgow-Blatchford Bleeding Score), ${ }^{60}$ or where a diagnosis has been reached, for example the CURB-65 score in community acquired pneumonia. ${ }^{61}$

\section{Point of care testing in SDEC}

Where diagnostic testing is required, point of care (POC) testing may facilitate rapid availability of results, shortening assessment pathways by reducing test turnaround time. Use of POC d-dimer testing to exclude deep vein thrombosis and PE is well established, with POC test accuracy comparable to laboratory testing. ${ }^{62,63}$ Highsensitivity POC troponin tests have been developed, but diagnostic performance requires further evaluation. ${ }^{44}$ Some POC investigations replace standard diagnostic tests and comparable performance must be demonstrated, while some provide additional assessment, such as point-of-care ultrasound (POCUS). POCUS has increasing evidence of utility in a range of presentations, ${ }^{63-65}$ but requires appropriately trained staff, and current availability in acute and emergency medicine settings varies. ${ }^{7,66}$

\section{SDEC and virtual wards}

A middle ground may exist, where risk of deterioration does not necessitate hospital admission, but care requirements exceed standard community provision. Early assessment could identify patients for discharge with increased outpatient support, with follow-up via home visits, telephone consultation or remote monitoring.

Home monitoring following early discharge of patients with chronic obstructive pulmonary disease with low mortality risk ${ }^{67}$ may reduce healthcare costs, without increasing readmissions or death. ${ }^{68}$ Previous evidence suggests discharge with 'virtual ward' support may decrease readmissions in frail older adults; ${ }^{69}$ however, this is compared to discharge with usual care and whether this approach could facilitate discharge in patients who would otherwise have been admitted was not assessed. Current evidence is limited to single centre, often observational studies ${ }^{68-70}$ and evidence from large multicentre trials is lacking.

Some centres have rapidly developed and implemented ambulatory pathways for patients with COVID-19, avoiding inpatient admission for those at low risk of deterioration. ${ }^{71,72}$ Pathways often combine routinely measured clinical features with 'rapid walk tests' identifying falling oxygen saturations on walking. ${ }^{71,73}$ Some ambulatory pathways included virtual review, providing pulse oximeters for home oxygen saturation monitoring. ${ }^{74}$ Again, evidence is limited to observational studies without control groups, but readmission appears to occur in approximately $11 \%$ of patients. ${ }^{71}$

Although these pathways may reduce pressure on acute services, and have positive patient feedback, ${ }^{71}$ the impact of delivering and supporting an additional service must be considered. Delivering ambulatory pathways and virtual reviews requires trained healthcare professionals. Healthcare staffing is a finite pool, and those with the skills to deliver these services are likely already delivering SDEC in other areas. Redistributing time and resource to new services may reduce ability to deliver existing services and thorough health economic evaluation is needed to assess the wider impact and costs of new services, alongside assessment of clinical benefit. 


\section{Knowledge gaps and research priorities}

Further research is needed to understand how SDEC can deliver the greatest benefit to both patients and the healthcare system.

First, greater understanding of the different models currently deployed across centres is needed, including the underlying reasons for the chosen service structure. A common model may not be possible across diverse healthcare settings, but agreed patient selection criteria and common performance indicators would facilitate comparison. Although key indicators for SDEC are recommended, ${ }^{11}$ outcomes assessing impact (including death, re-presentation, admission, and patient experience) are not reported or compared nationally. Comparing internationally, while there may be differences in health service structure, there are similarities in healthcare demand, ${ }^{75}$ and SDEC models used should be evaluated in comparison to alternative approaches utilised in other countries, for instance the increased primary care services offered in the Netherlands. ${ }^{76}$

Second, strategies to identify suitability for SDEC require wider validation. Further evidence should demonstrate how screening for SDEC can be most effectively incorporated into referral pathways, including where and when this screening occurs in admission pathway, and by whom, including the level of clinical experience or training in specific scoring systems required. Currently suggested risk scoring systems have been derived in local populations, and headto-head comparison of performance in wider regions with diverse demographics is needed, alongside assessment of whether new acuity scores (such as NEWS2) improve performance, and whether these simple scores could be supplemented in more digitally mature settings, enabling more stratified or personalised risk scoring. Reassurance that these scores can be used safely, predictably identifying patients at low risk of death or adverse outcome, must be shown through multicentre, prospective validation, in healthcare services that are representative of all centres where the scores would be used. Additional factors not included in these scoring systems are known to be associated with mortality after discharge from the emergency department, including levels of comorbidity, ${ }^{77,78}$ dependence in activities of daily living, ${ }^{79}$ and specific symptoms such as dyspnoea, ${ }^{80}$ fatigue, ${ }^{81}$ and recurrent falls. ${ }^{78}$ How these factors should be incorporated into streaming processes for medical admissions that utilise scoring systems requires assessment. The impact of scoring systems on access to SDEC for patient cohorts with different risk profiles, including pregnant patients and older adults, also needs evaluation.

Third, research may point to an agreed list of minimal additional services or tools required to optimise SDEC, such as POC testing, POCUS or specific out-reach services such as OPAT. Virtual wards may offer potential pathways, combining remote medical review and structured safety-netting without requiring inpatient admission.

The proportion of medical patients that may benefit from a SDEC service is unknown, and must be assessed alongside these other factors. Understanding the impact of proposed service models on defined patient outcomes and health service delivery is important, including the expected benefit to patients, but also staffing and infrastructure implications. Health economic analysis of different models would inform cost-effective healthcare choices.

\section{Conclusion}

SDEC is a current priority in NHS acute care service provision, aiming to reduce hospital admission for selected patients and therefore inpatient service demands. However, there remain several unanswered questions.
To understand how systems can be effectively implemented, an evaluation of clinical benefit is needed. Whether greater benefit would be gained from standardisation across healthcare settings, or pathways adapted to local population demographics and healthcare needs, is unclear. The potential wider repercussions of any new system must be considered, with health economic evaluation of potential impacts on acute care services. This will build an evidence base to guide the delivery of safe and effective SDEC.

\section{Key practice implications}

> Same day emergency care (SDEC) delivers assessment, investigation and treatment without overnight admission to an inpatient hospital bed.

> Structure of SDEC services varies nationally within the UK, and there is no clear evidence regarding the optimum way to design these services.

> Scoring systems have been suggested to identify patients from unselected medical admissions suitable for SDEC services, including the Glasgow Admission Prediction Score (GAPS) and the Amb Score.

$>$ When considering use of a scoring system to identify patients for SDEC, local population demographics must be considered as these can impact score performance, and local assessment of performance may be needed before implementation.

> SDEC pathways can be especially effective for specific conditions, such as suspected cardiac chest pain with validated risk stratification tools and suspected PE if at low risk of mortality, determined by PESI or sPESI scoring system.

> Additional services may facilitate the delivery of SDEC, such as virtual wards, but the impact of running an additional service on delivery of current services should be considered.

> There remain multiple gaps in our knowledge about how best to structure SDEC services and identify appropriate patients, to gain maximum benefit for patients and for healthcare services.

\section{References}

1 NHS England. A\&E attendances and emergency admission. www. england.nhs.uk/statistics/statistical-work-areas/ae-waiting-times-andactivity/ [Accessed 26 November 2021].

2 Royal College of Physicians. Acute medical care. The right person, in the right setting - first time. Report of the Acute Medicine Task Force. RCP, 2007.

3 Holland M, Subbe C, Atkin C et al. Society for Acute Medicine Benchmarking Audit 2019 (SAMBA19): Trends in acute medical care. Acute Med 2020;19:209-19.

4 Wyatt S, Child K, Hood A, Cooke M, Mohammed MA. Changes in admission thresholds in English emergency departments. Emerg Med J 2017:34:773.

5 Office for National Statistics. Latest data and analysis on coronavirus (COVID-19) in the UK and its effect on the economy and society. www. ons.gov.uk/peoplepopulationandcommunity/healthandsocialcare/ conditionsanddiseases [Accessed 26 November 2021].

6 Poteliakhof E, Thompson J. Emergency bed use: what the numbers tell us. King's Fund, 2011. www.kingsfund.org.uk/sites/default/files/ data-briefing-emergency-bed-use-what-the-numbers-tell-us-emmipoteliakhoff-james-thompson-kings-fund-december-2011.pdf [Accessed 26 November 2021].

7 Society for Acute Medicine. Society for Acute Medicine Benchmarking Audit 2021 - SAMBA2021 Report. SAM, 2021. Available from www. acutemedicine.org.uk/samba-2021-report/ [Accessed 26 November 2021]. 
8 NHS England. Transforming urgent and emergency care services in England. NHSE, 2015. www.england.nhs.uk/wp-content/ uploads/2015/06/trans-uec.pdf [Accessed 26 November 2021].

9 NHS Improvement and the Ambulatory Emergency Care Network. Same-day emergency care: clinical definition, patient selection and metrics. NHS England, 2018. www.england.nhs.uk/wp-content/ uploads/2021/05/aec-same-day-emergency-care-clinical-definitionpatient-selection-metrics.pdf [Accessed 26 November 2021].

10 Royal College of Physicians. Acute Care Toolkit 10: Ambulatory Emergency Care. RCP, 2015. Available from www.rcplondon.ac.uk/ guidelines-policy/acute-care-toolkit-10-ambulatory-emergency-care [Accessed 26 November 2021].

11 Society for Acute Medicine and the Royal College of Physicians of Edinburgh. Standards for ambulatory emergency care. RCPE, 2019. www.rcpe.ac.uk/sites/default/files/ambulatory_care_report.pdf [Accessed 26 November 2021].

12 NHS Ambulatory Emergency Care Network. Directory of ambulatory emergency care for adults (version 6). AECN, 2018. Available from www.ambulatoryemergencycare.org.uk/BAAEC/BAAEC-Resources/ AEC-Directory [Accessed 26 November 2021].

13 NHS England. Health Building Note 15-02: Facilities for same day emergency care/ambulatory emergency care. NHSE, 2021. Available from www.england.nhs.uk/publication/facilities-for-same-dayemergency-care-ambulatory-emergency-care-hbn-15-02/ [Accessed 26 November 2021].

14 Atkin C, Knight T, Subbe C et al. Acute care service performance during winter: report from the winter SAMBA 2020 national audit of acute care. Acute Med 2020;19:220-9.

15 Royal College of Emergency Medicine. The RCEM ambulatory emergency care toolkit. RECM, 2019. https://rcem.ac.uk/wp-content/ uploads/2021/10/RCEM_Ambulatory_Emergency_Care_Toolkit_ Feb2019.pdf [Accessed 26 November 2021].

16 Atkin C, Prinja P, Banerjee A, Holland M, Lasserson D. Provision of acute medicine services for pregnant women in UK hospitals: Data from the Society for Acute Medicine Benchmarking Audit 2019. Obstet Med 2021:14:83-8.

17 Chapman ALN, Patel S, Horner C et al. Updated good practice recommendations for outpatient parenteral antimicrobial therapy (OPAT) in adults and children in the UK. JAC Antimicrob Resist 2019:1:dlz026.

18 National Health Service. The NHS Long Term Plan. NHS, 2019

19 Reschen ME, Raby J, Bowen J et al. A retrospective analysis of outcomes in low- and intermediate-high-risk pulmonary embolism patients managed on an ambulatory medical unit in the UK.ERJ Open Res 2019:5:00184-2018.

20 Royal College of Physicians. Future hospital: Caring for medical patients. RCP, 2013. Available from www.rcplondon.ac.uk/projects/ outputs/future-hospital-commission [Accessed 26 November 2021]

21 NHS Ambulatory Emergency Care Network. Case studies. www. ambulatoryemergencycare.org.uk/Programmes/AEC-Programme/ Case-Studies [Accessed 26 November 2021].

22 Reschen ME, Bowen J, Singh S et al. Process of care and activity in a clinically inclusive ambulatory emergency care unit: progressive effect over time on clinical outcomes and acute medical admissions. Future Healthc ] 2020;7:234-40.

23 Hamad MMAA, Connolly VM. Ambulatory emergency care improvement by design. Clin Med 2018;18:69-74.

24 Ala L, Mack J, Shaw R et al. Selecting ambulatory emergency care (AEC) patients from the medical emergency in-take: the derivation and validation of the Amb score. Clin Med 2012;12:420-6.

25 Thompson A, Wennike N. Testing the AMB score - can it distinguish patients who are suitable for ambulatory care? Clin Med 2015:15:222-4.

26 Cameron A, Rodgers K, Ireland A, Jamdar R, McKay GA. A simple tool to predict admission at the time of triage. Emerg Med J 2015;32:174

27 Cameron A, Ireland AJ, McKay GA, Stark A, Lowe DJ. Predicting admission at triage: are nurses better than a simple objective score? Emerg Med J 2017;34:2-7.
28 Cameron A, Jones D, Logan E, O’Keeffe CA, Mason SM, Lowe DJ. Comparison of Glasgow Admission Prediction Score and Amb Score in predicting need for inpatient care. Emerg Med J 2018;35:247-51.

29 Office for National Statistics. Regional ethnic diversity. www.ethnicityfacts-figures.service.gov.uk/uk-population-by-ethnicity/national-andregional-populations/regional-ethnic-diversity/latest [Accessed 26 November 2021]

30 Whyte B, Young M, Timpson K. Glasgow: health in a changing city. Glasgow Centre for Population Health, 2021. Available from www.gcph.co.uk/publications/996_health_in_a_changing_city_ glasgow_2021 [Accessed 26 November 2021].

31 Walsh D, Buchanan D, Douglas A et al. Increasingly diverse: the changing ethnic profiles of Scotland and Glasgow and the implications for population health. App/ Spatial Analysis 2019;12:983-1009.

32 Simpson L. Does Britain have plural cities? Dynamics of diversity: Evidence from the 2011 Census. University of Manchester, 2013.

33 Soto GJ, Martin GS, Gong MN. Healthcare disparities in critical illness. Crit Care Med 2013;41:2784-93.

34 Cortes-Ramirez J, Naish S, Sly PD, Jagals P. Mortality and morbidity in populations in the vicinity of coal mining: a systematic review. BMC Public Health 2018;18:721.

35 Buckley LF, Carter DM, Matta L et al. Intravenous diuretic therapy for the management of heart failure and volume overload in a multidisciplinary outpatient unit. JACC Heart Fail 2016;4:1-8.

36 Alghalayini KW. Effect of diuretic infusion clinic in preventing hospitalization for patients with decompensating heart failure. SAGE Open Med 2020;8:2050312120940094.

37 Elliot AJ, Cross KW, Fleming DM. Acute respiratory infections and winter pressures on hospital admissions in England and Wales 19902005. J Public Health 2008;30:91-8.

38 NHS Improvement. NHS review of winter 2017/18. NHSI, 2018.

39 Endo T, Yoshida T, Shinozaki T et al. Efficacy of prehospital National Early Warning Score to predict outpatient disposition at an emergency department of a Japanese tertiary hospital: a retrospective study. BMJ Open 2020;10:e034602.

40 Shaw J, Fothergill RT, Clark S, Moore F. Can the prehospital National Early Warning Score identify patients most at risk from subsequent deterioration? Emerg Med J 2017;34:533.

41 Royal College of Physicians. National Early Warning Score (NEWS) 2. RCP, 2017. Available from https://www.rcplondon.ac.uk/projects/ outputs/national-early-warning-score-news-2 [Accessed 26 November 2021].

42 NHS England. Patient Safety Alert: Resources to support the safe adoption of the revised National Early Warning Score (NEWS2). NHSE, 2018. Available from www.england.nhs.uk/publication/patient-safetyalert-safe-adoption-of-news2/ [Accessed 26 November 2021].

43 Turley A, Smith R, Shyam-Sundar A. The use of medical early warning scores in high-risk acute coronary syndrome patients in a district hospital setting. Crit Care 2006;10:P367-P.

44 National Institute for Health and Care Excellence. High-sensitivity troponin tests for the early rule out of NSTEMI. NICE, 2020. www. nice.org.uk/guidance/dg40 [Accessed 26 November 2021].

45 Blatchford O, Capewell S, Murray S, Blatchford M. Emergency medical admissions in Glasgow: general practices vary despite adjustment for age, sex, and deprivation. Br J Gen Pract 1999:49:551-4.

46 Nuffield Trust. Potentially preventable emergency admissions 2021. Nuffield Trust, 2021. www.nuffieldtrust.org.uk/resource/potentiallypreventable-emergency-hospital-admissions [Accessed 26 November 2021].

47 Roffi M, Patrono C, Collet J-P et al. 2015 ESC Guidelines for the management of acute coronary syndromes in patients presenting without persistent ST-segment elevation: Task Force for the Management of Acute Coronary Syndromes in Patients Presenting without Persistent ST-Segment Elevation of the European Society of Cardiology (ESC). Eur Heart J 2016;37:267-315.

48 National Institute for Health and Care Excellence. Recent-onset chest pain of suspected cardiac origin: assessment and diagnosis. NICE, 2010. www.nice.org.uk/guidance/cg95 [Accessed 26 November 2021]. 
49 Than M, Flaws D, Sanders S et al. Development and validation of the Emergency Department Assessment of Chest pain Score and $2 \mathrm{~h}$ accelerated diagnostic protocol. Emerg Med Australas 2014;26:34-44.

50 Backus BE, Six AJ, Kelder JC et al. Chest pain in the emergency room: a multicenter validation of the HEART Score. Crit Pathw Cardiol 2010;9:164-9.

51 Antman EM, Cohen M, Bernink PJ et al. The TIMI risk score for unstable angina/non-ST elevation MI: A method for prognostication and therapeutic decision making. JAMA 2000;284:835-42.

52 Body R, Morris N, Reynard C, Collinson PO. Comparison of four decision aids for the early diagnosis of acute coronary syndromes in the emergency department. Emerg Med J 2020;37:8-13.

53 Chiang $\mathrm{C}-\mathrm{H}$, Chiang $\mathrm{C}-\mathrm{H}$, Lee $\mathrm{GH}$ et al. Safety and efficacy of the European Society of Cardiology 0/1-hour algorithm for diagnosis of myocardial infarction: systematic review and meta-analysis. Heart 2020:106:985

54 Howard L, Barden S, Condliffe R et al. British Thoracic Society Guideline for the initial outpatient management of pulmonary embolism (PE). Thorax 2018;73:ii1-ii29.

55 Aujesky D, Obrosky DS, Stone RA et al. Derivation and validation of a prognostic model for pulmonary embolism. Am J Respir Crit Care Med 2005;172:1041-6.

56 Aujesky D, Perrier A, Roy PM et al. Validation of a clinical prognostic model to identify low-risk patients with pulmonary embolism. J Intern Med 2007:261:597-604.

57 Jiménez D, Aujesky D, Moores L et al. Simplification of the pulmonary embolism severity index for prognostication in patients with acute symptomatic pulmonary embolism. Arch Intern Med 2010;170:1383-9.

58 British Thoracic Society Standards of Care Committee Pulmonary Embolism Guideline Development Group. British Thoracic Society guidelines for the management of suspected acute pulmonary embolism. Thorax 2003;58:470-83.

59 Davidson I. Outpatient investigation of 'low risk' hyperbilirubinaemia: Expanding the scope of our AEC. Society for Acute Medicine, 2020

60 Stanley AJ, Ashley D, Dalton HR et al. Outpatient management of patients with low-risk upper-gastrointestinal haemorrhage: multicentre validation and prospective evaluation. Lancet 2009;373:42-7.

61 Lim WS, van der Eerden MM, Laing R et al. Defining community acquired pneumonia severity on presentation to hospital: an international derivation and validation study. Thorax 2003;58:377.

62 Geersing GJ, Janssen KJM, Oudega R et al. Excluding venous thromboembolism using point of care D-dimer tests in outpatients: a diagnostic meta-analysis. BMJ 2009;339:b2990.

63 Goodacre S, Sampson F, Stevenson M et al. Measurement of the clinical and cost-effectiveness of non-invasive diagnostic testing strategies for deep vein thrombosis. Health Technol Assess 2006:10:1-168, iii-iv.

64 Beyer A, Lam V, Fagel B et al. Undifferentiated dyspnea with pointof-care ultrasound, primary emergency physician compared with a dedicated emergency department ultrasound team. J Emerg Med 2021;61:278-92

65 Teismann N, Lenaghan P, Nolan R, Stein J, Green A. Point-of-care ocular ultrasound to detect optic disc swelling. Acad Emerg Med 2013;20:920-5

66 Quinn AD, Dixon D, Meenan BJ. Barriers to hospital-based clinical adoption of point-of-care testing (POCT): A systematic narrative review. Crit Rev Clin Lab Sci 2016:53:1-12.

67 Steer J, Gibson J, Bourke SC. The DECAF Score: predicting hospital mortality in exacerbations of chronic obstructive pulmonary disease. Thorax 2012;67:970-6.
68 Echevarria C, Gray ], Hartley T et al. Home treatment of COPD exacerbation selected by DECAF score: a non-inferiority, randomised controlled trial and economic evaluation. Thorax 2018:73:713-22.

69 Leung DYP, Lee DT-F, Lee IFK et al. The effect of a virtual ward program on emergency services utilization and quality of life in frail elderly patients after discharge: a pilot study. Clin Interv Aging 2015;10:413-20.

70 Nadeem I, Light A, Donaldson C et al. Use of DECAF scoring system to facilitate early discharge in acute exacerbation of COPD patients: a quality improvement project at a district general hospital. Future Healthc J 2021;8:e123-e6.

71 Nunan J, Clarke D, Malakouti A et al. Triage Into the Community for COVID-19 (TICC-19) patients pathway - service evaluation of the virtual monitoring of patients with COVID pneumonia. Acute Med 2020;19:183-91.

72 Bell LC, Norris-Grey C, Luintel A et al. Implementation and evaluation of a COVID-19 rapid follow-up service for patients discharged from the emergency department. Clin Med 2021;21:e57-e62.

73 Bhasin A, Bregger M, Kluk M et al. Exertional hypoxia in patients without resting hypoxia is an early predictor of moderate to severe COVID-19. Intern Emerg Med 2021;16:2097-103.

74 Greenhalgh T, Knight M, Inada-Kim M et al. Remote management of COVID-19 using home pulse oximetry and virtual ward support. BM] 2021;372:n677.

75 Papanicolas I, Mossialos E, Gundersen A, Woskie L, Jha AK. Performance of UK National Health Service compared with other high income countries: observational study. BMJ 2019;367:16326.

76 Kremers MNT, Nanayakkara PWB, Levi M, Bell D, Haak HR. Strengths and weaknesses of the acute care systems in the United Kingdom and the Netherlands: what can we learn from each other? BMC Emerg Med 2019;19:40.

77 Bech CN, Brabrand M, Mikkelsen S, Lassen A. Risk factors associated with short term mortality changes over time, after arrival to the emergency department. Scand J Trauma Resusc Emerg Med 2018;26:29.

78 Hoang R, Sampsel K, Willmore A et al. Remember that patient you saw last week: characteristics and frequency of patients experiencing anticipated and unanticipated death following ED discharge. Can J Emerg Med 2021:23:767-71.

79 Magdelijns FJ, Schepers L, Pijpers E, Stehouwer CD, Stassen PM. Unplanned readmissions in younger and older adult patients: the role of healthcare-related adverse events. Eur J Med Res 2016;21:35.

$80 \mathrm{Na} \mathrm{S}, \mathrm{Cho}$ Y, Lim TH et al. Risk factors and causes of short-term mortality after emergency department discharge in older patients: using nationwide health insurance claims data. Ann Geriatr Med Res 2019:23:133-40.

81 Obermeyer Z, Cohn B, Wilson M, Jena AB, Cutler DM. Early death after discharge from emergency departments: analysis of national US insurance claims data. BMJ 2017;356:j239.

82 Patel A, Hassan S, Ullah A, Hamid T, Kirk H. Early triaging using the Modified Early Warning Score (MEWS) and dedicated emergency teams leads to improved clinical outcomes in acute emergencies. Clin Med 2015;15:s3.

Address for correspondence: Dr C Atkin, Birmingham Acute Care Research Group, Institute of Inflammation and Ageing, University of Birmingham, Edgbaston, Birmingham,

B15 2GW, UK

Email: c.atkin@nhs.net

Twitter: @catatkin 